\title{
A multibiomarker approach highlights effects induced by the human pharmaceutical gemfibrozil to gilthead seabream Sparus aurata
}

\author{
A. Barreto ${ }^{a, *}$, L.G. Luis ${ }^{a}$, P. Paíga ${ }^{b}$, L.H.M.L.M. Santos ${ }^{\mathrm{b}, c}$, C. Delerue-Matos ${ }^{\mathrm{b}}$, A.M.V.M. Soares ${ }^{\mathrm{a}}$, \\ K. Hylland ${ }^{\mathrm{d}}$, S. Loureiro ${ }^{\mathrm{a}}$, M. Oliveira ${ }^{\mathrm{a}}$ \\ a Department of Biology \& CESAM, University of Aveiro, 3810-193, Aveiro, Portugal \\ ${ }^{\mathrm{b}}$ REQUIMTE/LAQV, Instituto Superior de Engenharia do Porto, Instituto Politécnico do Porto, Rua Dr. António Bernardino de Almeida, 431, 4200-072, Porto, Portugal \\ ${ }^{c}$ Present affiliation: Catalan Institute for Water Research (ICRA), Carrer Emili Grahit 101, 17003, Girona, Spain \\ d Department of Biosciences, University of Oslo, PO Box 1066, N-0316, Oslo, Norway
}

\begin{abstract}
A B S T R A C T
Lipid regulators are among the most prescribed human pharmaceuticals worldwide. Gemfibrozil, which belongs to this class of pharmaceuticals, is one of the most frequently encountered in the aquatic environment. However, there is limited information concerning the mechanisms involved in gemfibrozil effects to aquatic organisms, particularly to marine organisms. Based on this knowledge gap, the current study aimed to assess biochemical and behavioral effects following a sublethal exposure to gemfibrozil $\left(1.5,15,150,1500\right.$ and $\left.15,000 \mu \mathrm{L} \mathrm{L}^{-1}\right)$ in the estuarine/marine fish Sparus aurata. After the exposure to $1.5 \mu \mathrm{g} \mathrm{L}^{-1}$ of gemfibrozil, fish had reduced ability to swim against a water flow and increased lipid peroxidation in the liver. At concentrations between $15-15,000 \mu \mathrm{g} \mathrm{L}^{-1}$, the activities of some enzymes involved in antioxidant defense were induced, appearing to be sufficient to prevent oxidative damage. Depending on the organ, different responses to gemfibrozil were displayed, with enzymes like catalase being more stimulated in gills, whereas glutathione peroxidase was more activated in liver. Although there were no obvious concentration-response relationships, the integrated biomarker response version 2 (IBRv2) analysis revealed that the highest concentrations of gemfibrozil (between $150-15,000 \mu \mathrm{g} \mathrm{L}^{-1}$ ) caused more alterations. All the tested concentrations of gemfibrozil induced effects in $S$. aurata, in terms of behavior and/or oxidative stress responses. Oxidative damage was found at a concentration that is considered environmentally relevant, suggesting a potential of this pharmaceutical to impact fish populations.
\end{abstract}

Keywords:
Fibrates
Seabream
Behavior
Biomarkers
Oxidative damage

\section{Introduction}

Pharmaceuticals are considered emerging environmental contaminants of concern due to their high consumption and continuous environmental release (as parental compound and/or metabolites). This is both due to inefficient wastewater treatment processes and, for some substances, high environmental persistence and low degradation rates (Andreozzi et al., 2003; Fent et al., 2006; Schmidt et al., 2011). The prescription rates of lipid regulators are continually increasing and gemfibrozil (GEM) is among the most widely used (Al-Habsi et al., 2016; Prindiville et al., 2011). GEM was approved by the Food and Drug Administration (FDA) in 1976 for use by humans to reduce serum lipids. It reduces the levels of triglycerides, very low-density lipoprotein (VLDL, "bad cholesterol") and low-density lipoprotein (LDL, "bad cholesterol") and increases high-density lipoprotein (HDL, "good cholesterol") (Kim et al., 2017). In North America and Europe these drugs are widely used to control hyperlipidaemia resulting from the western diet (Ido et al., 2017). In the United States, in 2009, GEM was prescribed over 500000 times (Bulloch et al., 2012; Jackevicius et al., 2011). Being among the most prescribed human pharmaceuticals, lipid regulators are frequently reported in wastewater and surface waters (Andreozzi et al., 2003; Gros et al., 2006; Lin and Reinhard, 2005; Sanderson et al., 2003; Schmidt et al., 2011; Togola and Budzinski, 2007). In Europe, GEM has been found at concentrations up to $4.76 \mathrm{\mu g} \mathrm{L}^{-1}$ in wastewater treatment plant effluents (Andreozzi et al., 2003) and up to $1.5 \mu \mathrm{g} \mathrm{L}^{-1}$ in surface waters (Fang et al., 2012). In marine ecosystems, GEM is also among the most frequently detected compounds, with concentrations between 1 and $758 \mathrm{ng} \mathrm{L}^{-1}$ in seawater (Gaw et al., 2014; Vidal-Dorsch et al., 2012). Despite its presence in aquatic ecosystems, there is still limited information concerning mechanisms of toxicity for GEM to aquatic organisms, particularly for marine fish.

\footnotetext{
* Corresponding author

E-mail address: abarreto@ua.pt (A. Barreto).
} 
Earlier studies on GEM exposure to aquatic organisms have revealed a potential of this pharmaceutical to induce alterations of biochemical and behavioral endpoints (Al-Habsi et al., 2016; Fraz et al., 2018; Henriques et al., 2016; Mimeault et al., 2006; Prindiville et al., 2011; Quinn et al., 2011, 2008; Schmidt et al., 2011; Skolness et al., 2012; Zurita et al., 2007). In zebrafish (Danio rerio), GEM was found to impair hatching success and embryonal development, change locomotor activity and reduce survival, with a reported 96-h $\mathrm{LC}_{50}$ ( $50 \%$ lethal effect concentration) of $11.01 \mathrm{mg} \mathrm{L}^{-1}$ (Henriques et al., 2016). GEM activated cholinesterase in the PLHC-1 cell lines of the fish clearfin livebearer (Poeciliopsis lucida) (Zurita et al., 2007) and enzymes involved in oxidative stress of goldfish (Carassius auratus), as well as increased lipid peroxidation (Mimeault et al., 2006). GEM has furthermore been reported to decrease plasma testosterone levels in freshwater goldfish (Carassius auratus) (Mimeault et al., 2005) and to activate antioxidant enzymes and modulate metallothionein expression in blue mussel (Mytilus spp.) (Schmidt et al., 2011). The ability of GEM to induce behavioral alterations has also been reported for the freshwater cnidarian Hydra attenuata (Quinn et al., 2008). GEM exposure increased growth and reproduction of Daphnia magna (Salesa et al., 2017; Steinkey et al., 2018). The effect of GEM on lipid metabolism was previously reported for the freshwater fish fathead minnow (Pimephales promelas) (Skolness et al., 2012) and rainbow trout (Oncorhynchus mykiss) (Prindiville et al., 2011). In marine fish, GEM has been reported to affect antioxidant defenses in sole (Solea senegalensis) (Solé et al., 2014) and to inhibit the activity of P450-catalysed pathways of yellow European eel (Anguilla anguilla) (Lyssimachou et al., 2014). In these studies fish were exposed through intraperitoneal injection. In the gilthead seabream (Sparus aurata), GEM has been reported to induce genotoxic effects at a concentration frequently detected in the environment $\left(1.5 \mu \mathrm{g} \mathrm{L}^{-1}\right.$ ) (Barreto et al., 2017). It affected transcription of key genes involved in lipid homeostasis and was characterized as a stress-inducing agent (Teles et al., 2016). It is, however, not known if GEM alters enzymatic activities associated with oxidative stress and biotransformation and whether exposure to GEM also affects behavior.

Considering the existing knowledge gaps concerning the mechanistic effects of GEM exposure to marine fish, the gilthead seabream (Sparus aurata) was selected as a model species and several biomarkers were included in an integrated assessment of possible effects. This top predator is widespread in Atlantic and Mediterranean coastal waters, with a high economic importance for both fishery and aquaculture, being one of the most consumed fish in the Mediterranean area (Teles et al., 2016). Furthermore, $S$. aurata has previously been shown to be sensitive to short-term exposure to GEM as demonstrated by increased DNA damage and increased cortisol levels (Barreto et al., 2017; Teles et al., 2016). Effects of GEM were determined following 96-h waterborne exposure by assessing swimming ability, which may provide information on the ability of fish to escape predators, to chase prey and escape pernicious conditions, and biomarkers involved in neurotransmission (cholinesterase - ChE), biotransformation and antioxidant defenses (catalase (CAT), glutathione $S$-transferases (GST), glutathione peroxidase (GPx) and glutathione reductase (GR)) as well as oxidative damage, i.e. lipid peroxidation (LPO). This set of biomarkers was chosen to assess the general health status of fish focusing on the ability to respond to oxidative challenge, maintain biotransformation and prevent damage in order to maintain fitness. This approach has been previously adopted by other authors using a battery of behavioral and biochemical biomarkers, such as ChE, GST, CAT activities and LPO levels to assess the effects of toxic metals and bisphenol A to $S$. aurata (Souid et al., 2013, 2015). The purpose of the present study was thus to understand the potential effects of GEM to the marine fish $S$. aurata and the mechanisms of toxicity involved.

\section{Material and methods}

\subsection{Chemicals}

All reagents used were of analytical grade obtained from SigmaAldrich (Germany), Bio-Rad (Germany) and Merck (Germany). GEM was acquired from Tokyo Chemical Industry Co., Ltd. (TCI) and the isotopically labelled standard gemfibozil-d6 was purchased from Santa Cruz Biotechnology (USA).

\subsection{Test organisms and acclimation}

Juvenile gilthead seabream (Sparus aurata), with a length of $9 \pm 0.5 \mathrm{~cm}$ and a weight of $8.1 \pm 0.6 \mathrm{~g}$, from an aquaculture facility (Santander, Spain), were acclimated for 4 weeks in aquaria with aerated and filtered (Eheim filters) arti ficial seawater (ASW, Ocean Fish, Prodac). This water was prepared by dissolving the salt in reverse osmosis purified water to obtain a salinity of 35 , in a controlled room temperature $\left(20^{\circ} \mathrm{C}\right)$ and natural photoperiod. During the acclimation period, animals were fed daily with commercial fish food (Sorgal, Portugal) at a ratio of $1 \mathrm{~g}$ per $100 \mathrm{~g}$ of fish. The ASW used to maintain fish during the acclimation period was also used during the toxicity test.

\subsection{Experimental design}

All experimental procedures were carried out following the Portuguese and European legislation (authorization N421/2013 of the Portuguese legal authorities). Animal handling was performed by an accredited researcher. The bioassay followed, in general, the OECD guidelines for fish acute bioassays (OECD, 1992). A stock solution of GEM $\left(50 \mathrm{~g} \mathrm{~L}^{-1}\right)$ was prepared, daily, in dimethyl sulfoxide (DMSO) due to its limited water solubility. DMSO was selected as a solvent due to its widespread use in several toxicological studies (Mimeault et al., 2006; Zurita et al., 2007; Quinn et al., 2008; Schmidt et al., 2011). Test solutions of GEM were prepared by dilution of the stock solution in ASW.

After the acclimation period, 70 fish were randomly distributed in the experimental aquaria, with ten fish per condition $(n=10)$ in the ratio $1 \mathrm{~g}$ of fish per $1 \mathrm{~L}$ of ASW. The experimental design included a negative control (seawater only), a solvent control (0.03\% DMSO, the maximal concentration of DMSO used in the GEM treatments) and five GEM concentrations: $1.5,15,150,1500$ and $15,000 \mu \mathrm{g} \mathrm{L}^{-1}$. Fish were exposed for $96 \mathrm{~h}$ as recommended by the OECD guideline for fish acute toxicity testing (203), without feeding. The lowest tested concentration of GEM was chosen because it is considered an environmentally relevant concentration, based on levels detected in surface waters (Fang et al., 2012). The concentration range used was based on 10-fold increases.

Daily, after checking fish mortality, behavior alterations and assessing the water parameters (temperature, salinity, conductivity, $\mathrm{pH}$ and dissolved oxygen), approximately $80 \%$ of the experimental media was renewed to circumvent GEM degradation and to reduce the buildup of excretion products. During the exposure time, photoperiod, temperature and aeration conditions were similar to those used in the acclimation period.

\subsection{Quantification of GEM in the experimental media}

Water samples were collected daily (at 0 and $24 \mathrm{~h}$ ) from each aquarium. GEM was extracted using solid phase extraction (SPE). Briefly, Strata X cartridges (200 mg, $3 \mathrm{~mL}$ ) (Phenomenex, USA) were conditioned with $5 \mathrm{~mL}$ methanol and $5 \mathrm{~mL}$ ultra-pure water. Then, $10 \mathrm{~mL}$ of water sample was percolated through the cartridge (3-5 $\left.\mathrm{mL} \mathrm{min}^{-1}\right)$, rinsed with $5 \mathrm{~mL}$ ultra-pure water and dried under vacuum $(20 \mathrm{~min})$. Finally, GEM was eluted from the cartridges with methanol $(10 \mathrm{~mL})$. Extracts were evaporated until dryness under a gentle stream of nitrogen and reconstituted with $1 \mathrm{~mL}$ acetonitrile/ ultra-pure water (30:70, v/v). Gemfibrozil-d6 $\left(10 \mu \mathrm{L}\right.$ of $5 \mathrm{mg} \mathrm{L}^{-1}$ in methanol) was added to the extract as internal standard. GEM analysis was performed on a Nexera UHPLC system with a triple-quadrupole mass spectrometer detector LCMS-8030 (Shimadzu Corporation, Kyoto, Japan). Chromatographic separation was achieved using a Kinetex C18 column $(2.1 \times 150 \mathrm{~mm}$ i.d., $1.7 \mu \mathrm{m}$ particle size $)$ from Phenomenex 
(USA) using $5 \mathrm{mM}$ ammonium acetate/ammonia buffer ( $\mathrm{pH}$ 8) as solvent $A$ and acetonitrile as solvent $B$ at a flow rate of $0.22 \mathrm{~mL} \mathrm{~min}^{-1}$. The gradient elution was performed as follows: initial conditions: $30 \% \mathrm{~B}$; 0-2.0 min, $30 \%-100 \% \mathrm{~B} ; 2.0-4.5 \mathrm{~min}$ maintained at $100 \% \mathrm{~B}$, 4.5-5.5 min return to initial conditions; and from 5.5 to $9.5 \mathrm{~min}$, reequilibration of the column. Column oven was set at $30^{\circ} \mathrm{C}$ and the autosampler was operated at $4^{\circ} \mathrm{C}$. The injection volume was $5 \mu \mathrm{L}$.

GEM was analysed in the negative ionization mode and quantification was performed in multiple reaction monitoring mode (MRM) using two transitions between the precursor ion and the most abundant fragment ions (MRM1: $249.00>121.15$ and MRM2: $249.00>127.05$ ). Quantification was performed by the internal standard calibration method. The method detection limit (MDL) for GEM in water was $4.0 \mathrm{ng} \mathrm{L}^{-1}$.

\subsection{Assessment of swimming performance}

After $96 \mathrm{~h}$ exposure, each fish was gently transferred to a $1.5 \mathrm{~m}$ long track race flume with $7 \mathrm{~cm}$ diameter with a running water flow of $20 \mathrm{~L} \mathrm{~min}^{-1}$ and induced to swim, generally following the procedure described by Oliveira et al. (2012). The time that animals were able to swim against the water flow was recorded. After this test, fish were put back into their original test aquaria where they stayed for $2 \mathrm{~h}$ before being used to determine biochemical endpoints.

\subsection{Preparation of biological material for biomarker determination}

After the recovery period, animals were anesthetized with tricaine methanesulfonate (MS-222), their length measured, weighed and euthanized by spinal section. Liver, gills, brain and muscle were taken from each animal, snap frozen in liquid nitrogen to prevent enzyme degradation and stored at $-80^{\circ} \mathrm{C}$ until further processing.

\subsubsection{Liver and gills}

Liver and gills were homogenized in potassium phosphate buffer (0.1 mM, pH 7.4), using an ultrasonic homogenizer (Sonifier 250, Branson sonicator). One aliquot of homogenate, for LPO determination, was transferred to a microtube with $4 \%$ BHT (2,6-dieter-butyl-4-metylphenol) in methanol, to prevent oxidation and stored at $-80^{\circ} \mathrm{C}$ until analysis. The remaining homogenate was used for post-mitochondrial supernatant (PMS) isolation. PMS was accomplished by centrifugation at $12000 \times \mathrm{g}$ for $20 \mathrm{~min}$ at $4{ }^{\circ} \mathrm{C}$. PMS aliquots were stored at $-80^{\circ} \mathrm{C}$ until the determination of CAT, GST, GPx and GR activities.

\subsubsection{Muscle and brain}

Muscle and brain were used for ChE activity determination. Tissues were homogenized in potassium phosphate buffer $(0.1 \mathrm{mM}, \mathrm{pH} 7.2)$, centrifuged at $3300 \times g$ for $3 \mathrm{~min}$ at $4^{\circ} \mathrm{C}$, supernatant was collected and stored at $-80^{\circ} \mathrm{C}$.

\subsection{Biochemical biomarker analysis}

Protein concentration was determined according to Bradford (1976), adapted to microplate, using bovine $\gamma$ - globulin as a standard.

\subsubsection{ChE activity}

ChE activity was determined according to the Ellman's method (Ellman et al., 1961) adapted to microplate (Guilhermino et al., 1996). The rate of thiocholine production was assessed at $412 \mathrm{~nm}$ as $\mathrm{nmol}$ of thiocholine formed per min per mg of protein using acetylthiocholine as substrate.

\subsubsection{CAT activity}

CAT activity was assayed as described by Claiborne (1985) and the variations in absorbance at $240 \mathrm{~nm}$, caused by the dismutation of hydrogen peroxide $\left(\mathrm{H}_{2} \mathrm{O}_{2}\right)$, were recorded. CAT activity was calculated as $\mu \mathrm{mol} \mathrm{H}_{2} \mathrm{O}_{2}$ consumed per min per mg of protein.

\subsubsection{GST activity}

GST activity was determined spectrophotometrically by the method of Habig et al. (1974) adapted to microplate (Frasco and Guilhermino, 2002), following the conjugation of the substrate, 1-chloro-2, 4-dinitrobenzene (CDNB), with reduced glutathione. Absorbance was recorded at $340 \mathrm{~nm}\left(25^{\circ} \mathrm{C}\right)$ and activity expressed as nmol CDNB conjugate formed per min per $\mathrm{mg}$ of protein.

\subsubsection{GPx activity}

GPx activity was measured according to the method described by Mohandas et al. (1984) as modified by Athar and Iqbal (1998). Oxidation of NADPH was recorded spectrophotometrically at $340 \mathrm{~nm}$ and the enzyme activity results expressed as nmol NADPH oxidized per min per $\mathrm{mg}$ of protein.

\subsubsection{GR activity}

GR activity was estimated according the method of Carlberg and Mannervik (1975) adapted to microplate (Lima et al., 2007), measuring NADPH disappearance at $340 \mathrm{~nm}$. GR activity was expressed as nmol of $\mathrm{NADP}^{+}$formed per min per $\mathrm{mg}$ of protein.

\subsubsection{LPO levels}

LPO levels were estimated by the formation of thiobarbituric acid reactive substances (TBARS) based on Ohkawa et al. (1979), adapted by Wilhelm Filho et al. (2001). Absorbance was measured at $535 \mathrm{~nm}$ and LPO levels were expressed as nmol of TBARS formed per $\mathrm{mg}$ of protein.

\subsection{Integrated biomarker response (IBR)}

To integrate all the results from the different tested biomarkers and to understand global responses, the IBR index was calculated according to Sanchez et al. (2013), using IBR version 2 (IBRv2). IBRv2 was designed to modify the IBR previously developed by Beliaeff and Burgeot (2002). The IBR was chosen to integrate the different biomarker responses into a numeric value (Devin et al., 2014). The assessed endpoints were combined into one general "stress index" to integrate biomarker data into a value representing the stress level at each tested concentration, based on the principle of reference deviation. Overall, data were log-transformed $(Y i)$ and the overall mean $(\mu)$ and standard deviation (s) calculated. Data was further standardized by subtracting the overall mean and dividing by the standard deviation as presented in the following equation:

$Z i=\left(\frac{y i-\mu}{s}\right)$

The difference between $\mathrm{Zi}$ and $\mathrm{Z0}$ (control) was calculated in order to determine A values. Representative results are shown as star plot charts indicating the deviation of all biomarkers in relation to the control (0) (Sanchez et al., 2013). In addition, data were analyzed using a weighing procedure for endpoints as previously described (Liu et al., 2013, 2015), assuming that a biochemical alteration has lower impact on the organism health than changes at an individual level. Behavior is considered as the outcome of many biological processes resultant from interactions between the organisms and the surrounding environment (Oliveira et al., 2015). Thus, biochemical biomarkers were weighted with a factor of one and behavior with a factor of three. More information about IBRv2 and the difference between this version and version 1 can be found in the supplementary information.

\subsection{Data analysis}

Data were tested for normality (Shapiro-Wilk test) and homogeneity of variance (Levene's test), using Sigma Plot 12.0 software package. Differences between controls (negative and solvent) were carried out using a Student $t$-test $(\mathrm{p}<0.05)$. Differences between treatments and controls were compared using one-way analysis of variance (ANOVA), 
followed by Dunnett's comparison test whenever applicable $(\mathrm{p}<0.05)$.

\section{Results and discussion}

\subsection{Quantification of GEM in the experimental media}

The analysis of GEM concentrations revealed that nominal concentrations of GEM differed 6-37\% from the results obtained by chemical analyses (Table S1). After $24 \mathrm{~h}$, GEM degradation was higher in the aquaria with the lowest concentrations, as previously presented (Barreto et al., 2017). Other authors also reported a decrease of GEM concentrations more evident in the lowest concentrations after 14-d exposure of goldfish (Mimeault et al., 2005). In that study, the initial concentrations 1.5 and $1500 \mu \mathrm{L} \mathrm{L}^{-1}$ gave measured concentrations of 0.34 and $851.9 \mu \mathrm{L} \mathrm{L}^{-1}$ after $14 \mathrm{~d}$, respectively. The observed decrease of GEM concentrations in the water can also be explained by the incorporation of GEM in the fish. In the study of Mimeault et al. (2005), the quantification of GEM in the plasma of goldfish exposed to 1500 and $10,000 \mu \mathrm{g} \mathrm{L}^{-1}$ revealed that, after $96 \mathrm{~h}$, GEM was present in concentrations higher than $75,000 \mu g \mathrm{~L}^{-1}$ for both treatments. After 14-d exposure, plasma concentrations of animals exposed to nominal concentrations of 1.5 and $1500 \mu \mathrm{g} \mathrm{L}^{-1}$ were 170 and $78,000 \mu \mathrm{g} \mathrm{L}^{-1}$, respectively (Mimeault et al., 2005).

\subsection{Biological responses}

The solvent DMSO did not induce significant effects when compared to the negative control ( $t$-test, $\mathrm{p}>0.05$ ) for any reported endpoint. Therefore, all GEM exposure data were compared to the negative control.

The ability of $S$. aurata to swim against a water flow (in terms of time of swimming) was significantly decreased (between 50 and 65\%; $\mathrm{p}<0.05$ ) in individuals exposed to GEM, relative to the control group (Fig. 1), highlighting behavior as a sensitive endpoint. The detected swimming performance impairment may have serious environmental consequences (Wolter and Arlinghaus, 2003). The basic activities of fish, such as predator-prey interactions, reproduction and migration, are completely dependent on the individuals' capacity for locomotion (Svendsen et al., 2015; Vieira et al., 2009). A decrease in locomotion was also reported for zebrafish larvae exposed to GEM concentrations equal to or higher than $1500 \mu \mathrm{L} \mathrm{L}^{-1}$ (Henriques et al., 2016). However, unlike in the present study, the locomotor activity decreased when GEM concentration increased (Henriques et al., 2016).

Altered swimming behavior may be associated with effects on

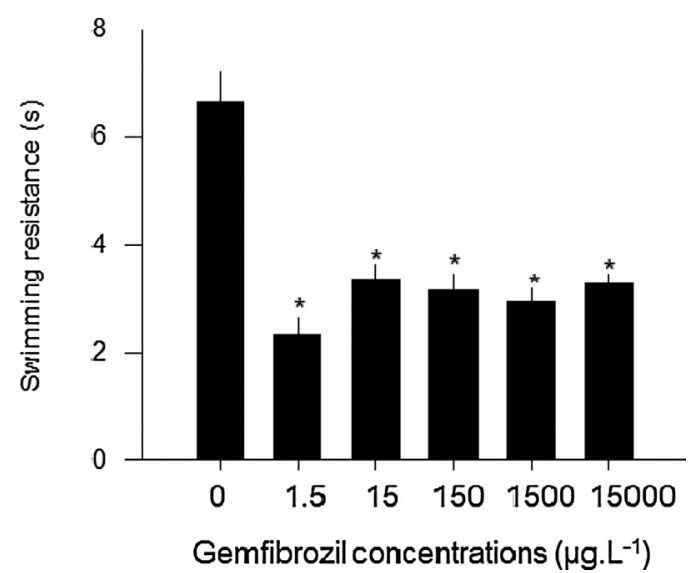

Fig. 1. Gemfibrozil effects on the swimming resistance of Sparus aurata $(n=10$ per condition) against a water flow (expressed as time in seconds (s) that the fish are able to swim) after $96 \mathrm{~h}$ exposure. Results are expressed as mean \pm standard error. *Significant differences to control (Dunnett's test, $\mathrm{p}<0.05$ ). neurotransmission. ChE activity is essential for the degradation of the neurotransmitter acetylcholine in cholinergic synapses and thus involved in a correct transmission of nerve impulses both in vertebrates and invertebrates (Pan et al., 2012; Sureda et al., 2018). Thus, it could be hypothesized that a decrease in ChE might be a possible explanation for the observed decrease in the swimming performance (HernándezMoreno et al., 2011). However, in the present study, ChE activity was not significantly altered at the tested concentrations (Fig. 2A and B), suggesting that other factors (e.g., decreased available energy associated with the need to metabolize GEM and to activate enzymatic processes or inadequate capacity to supply oxygen to tissues (Kennedy and Farrell, 2006)) may be involved in the detected behavioral alteration.

Oxidative stress is a mechanism of toxicity described for several environmental contaminants such as metals and pesticides (Lushchak, 2016). In the present study, CAT activity significantly increased (between 50 and 93\%) in the gills of fish exposed to concentrations higher than $1.5 \mu \mathrm{g} \mathrm{L}^{-1}(\mathrm{p}<0.05)$ (Fig. 3A). GR activity also significantly increased between 46 and $72 \%$ in gills $(p<0.05)$ in individuals exposed to concentrations of 15,150 and $1500 \mu \mathrm{g} \mathrm{L}^{-1}$ (Fig. 3D), but not under the highest exposure concentration. However, no significant alterations were found in terms GST and GPx activities of gills (Fig. 3B and $\mathrm{C}$, respectively).

In the liver, CAT activity was significantly increased (150\%) $\left(\mathrm{p}<0.05\right.$ ) in animals exposed to $15,000 \mu \mathrm{L} \mathrm{L}^{-1}$ (Fig. 4A) whereas no significant alterations were found in GST activity (Fig. 4B). GPx and GR activities significantly increased ( $\mathrm{p}<0.05$ ), between 156 and $243 \%$ (Fig. 4C) and 42-75\% (Fig. 4D), respectively, in concentrations higher than $1.5 \mu \mathrm{g} \mathrm{L}^{-1}$ of GEM. The activity of GST, involved in the detoxification of many xenobiotics and playing an important role in protecting tissues from oxidative stress, was not affected by exposure to GEM. However, the assessed enzymes involved in antioxidant defense (CAT, GPx and GR) were activated both in gills and liver in a tissue- and concentration-dependent manner. At concentrations of GEM higher than $15 \mu \mathrm{g} \mathrm{L}^{-1}$, some enzymatic activities were maintained (gills CAT and liver GR) or decreased (gills GR). These observed responses may be due to the negative feedback from excess of substrate or direct damage by oxidative modifications (Ceyhun et al., 2010; Rodrigues et al., 2016). On other hand, at concentrations between 150 and $15,000 \mu \mathrm{g} \mathrm{L}^{-1}$, fish may have also cope with this xenobiotic compound, resulting in similar responses at these three concentrations.

As the present study, previous studies with aquatic organisms have demonstrated the induction of oxidative stress by GEM (Mimeault et al., 2006; Schmidt et al., 2014, 2011), but a direct comparison between results is not straightforward due to differences in exposure duration, test organisms (species and their natural environment, including freshwater versus seawater), and in vivo versus in vitro studies. Teles et al. (2016) reported that the hepatic transcription of CAT, GPx and GST in $S$. aurata was not altered following $96 \mathrm{~h}$ exposure to GEM. However, the present study demonstrated that antioxidant enzymes (CAT, GPx and GR) were responsive to GEM exposure showing that evaluation of enzyme activity is key considering the complex regulatory mechanisms for gene expression that occurs at both post-transcriptional and post-translational levels.

As shown in Fig. 5B, peroxidative damage (assessed as TBARS levels) was only found in liver at $1.5 \mu \mathrm{g} \mathrm{L}^{-1}$. This concentration led to a $57 \%$ increase in TBARS levels compared to liver from the control group. In gills from fish exposed to 15 and $150 \mu \mathrm{L} \mathrm{L}^{-1}$ GEM there was a significant $(\mathrm{p}<0.05$ ) decrease in LPO levels, corresponding to 24 and $30 \%$ when compared to the control, respectively (Fig. 5A). The decreased LPO levels observed after exposure to GEM have earlier been reported for the digestive gland of marine mussels (Mytilus spp.) and shown to depend on exposure time (Schmidt et al., 2014). Increased (Mimeault et al., 2006) or unaltered (Quinn et al., 2011) LPO levels after the exposure to GEM were also previously reported for freshwater organisms, suggesting that the mechanisms of GEM toxicity are to a 
A)

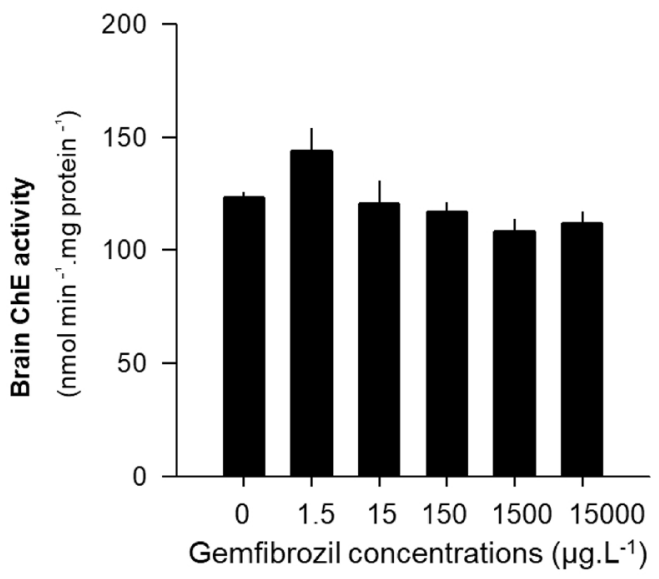

B)

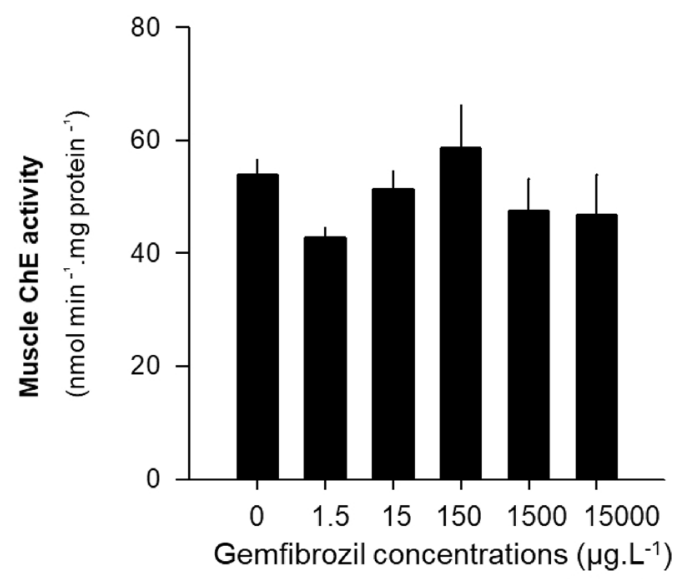

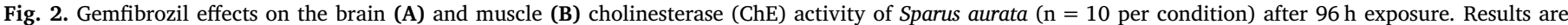
expressed as mean \pm standard error. *Significant differences to control (Dunnett's test, p < 0.05).

A)

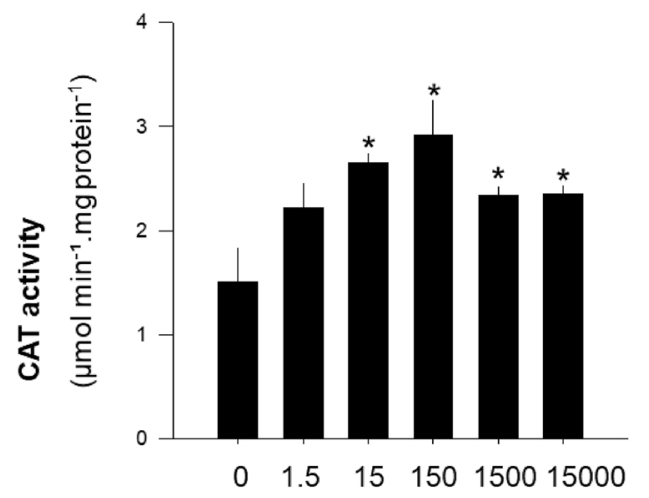

Gemfibrozil concentrations ( $\left.\mu \mathrm{g} \cdot \mathrm{L}^{-1}\right)$

C)

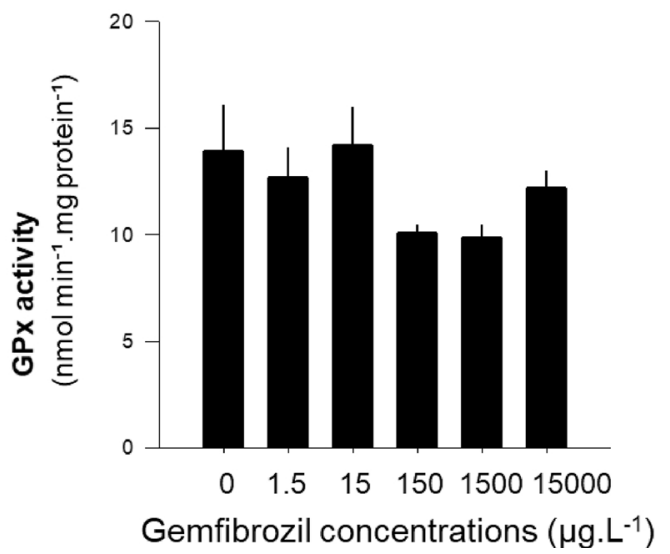

B)

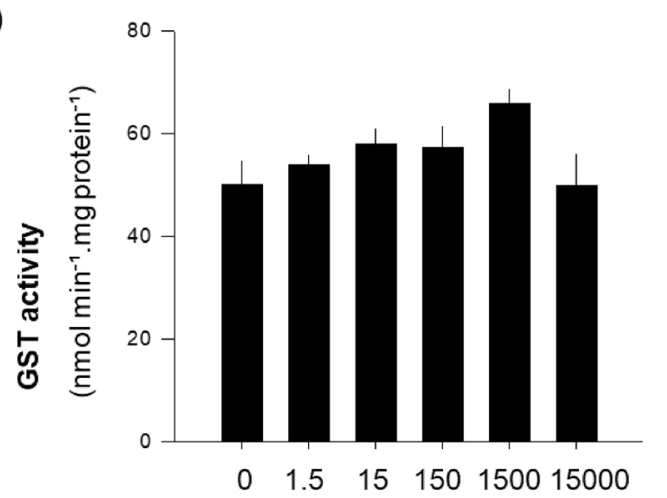

Gemfibrozil concentrations ( $\mu$ g. $\left.\mathrm{L}^{-1}\right)$

D)

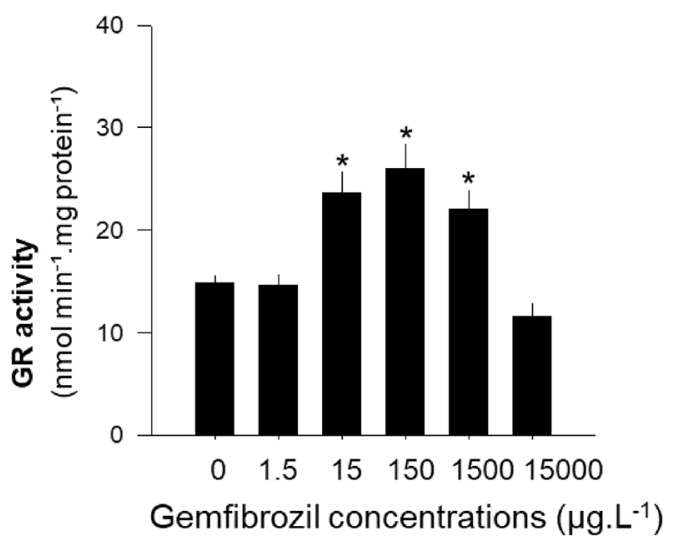

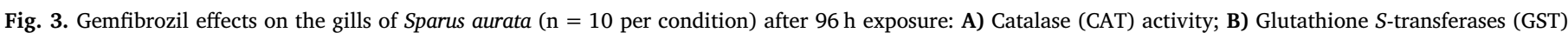

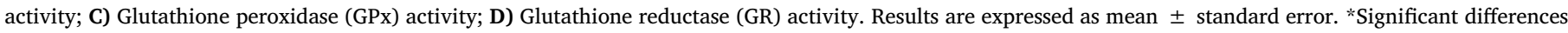
to control (Dunnett's test, $\mathrm{p}<0.05$ ).

large extent species-specific.

In the present study, $1.5 \mu \mathrm{g} \mathrm{L}^{-1}$ of GEM was able to induce oxidative damage in $S$. aurata without leading to significant alteration of antioxidant enzyme activity. At GEM concentrations higher than $1.5 \mu \mathrm{g} \mathrm{L}^{-1}$, activation of antioxidant defences appeared to be sufficient to prevent oxidative damage. Previous data involving GEM and other lipid regulators showed a high prevalence of peroxisome proliferation (even as an acute effect), indicating the possibility of occurrence of oxidative stress, which may lead to irreversible damage by lipid peroxidation (Nunes et al., 2004; Qu et al., 2001; Quinn et al., 2011). On other hand, the reported ability of GEM to reduce lipids may have also contributed to the observed LPO decrease (Ozansoy et al., 2001; Roy and Pahan, 2009; Sutken et al., 2006).

The analysis of antioxidant status and other stress responses in different tissues of organisms exposed to pollutants helps to understand the associated mechanisms of toxicity and predict the degree of effects at different levels of biological organization (Franco et al., 2006; Oliveira et al., 2008). In the present study, responses in gills and liver 
A)
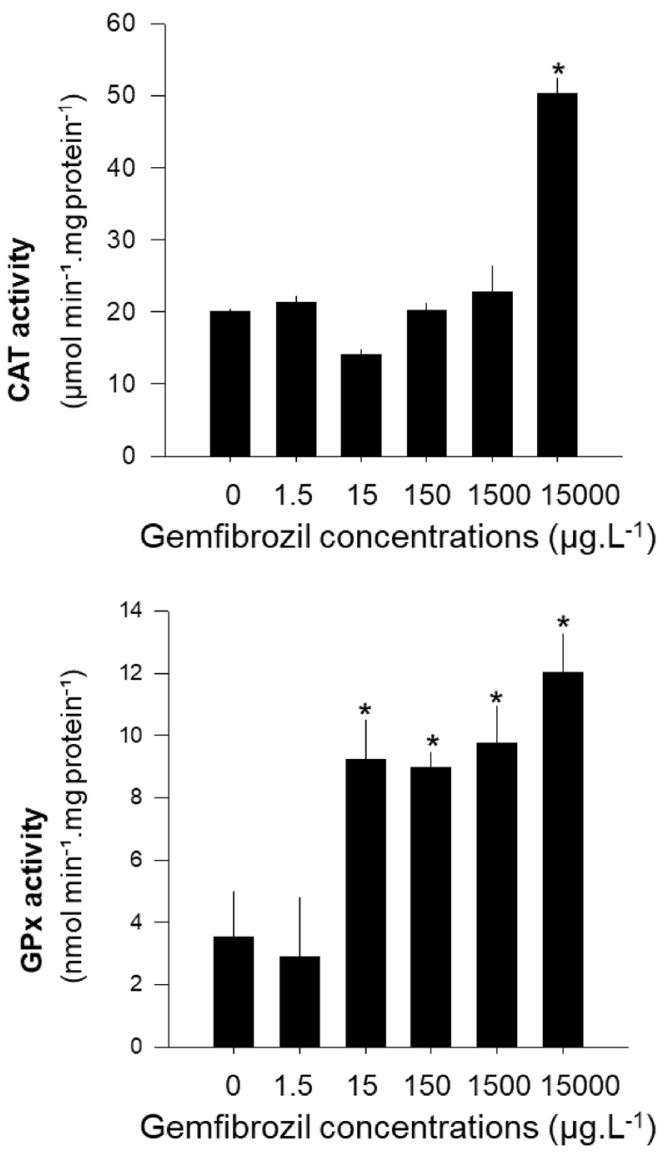

B)

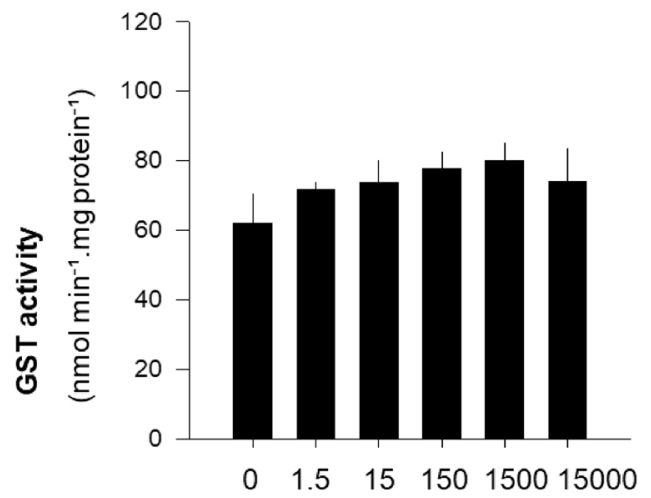

Gemfibrozil concentrations ( $\mu \mathrm{g} \cdot \mathrm{L}^{-1}$ )

D)

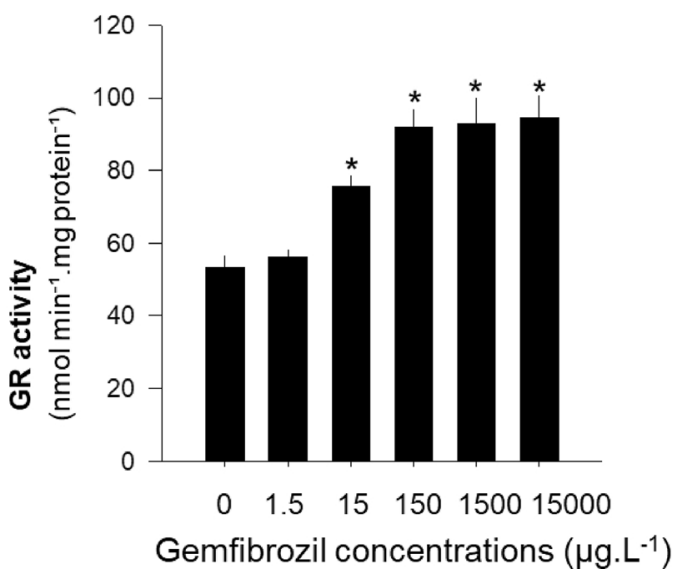

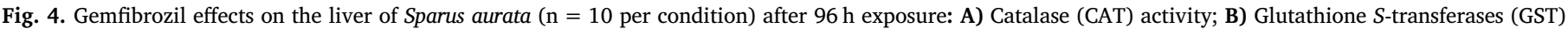

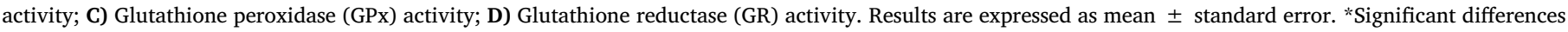
to control (Dunnett's test, $\mathrm{p}<0.05$ ).

A)

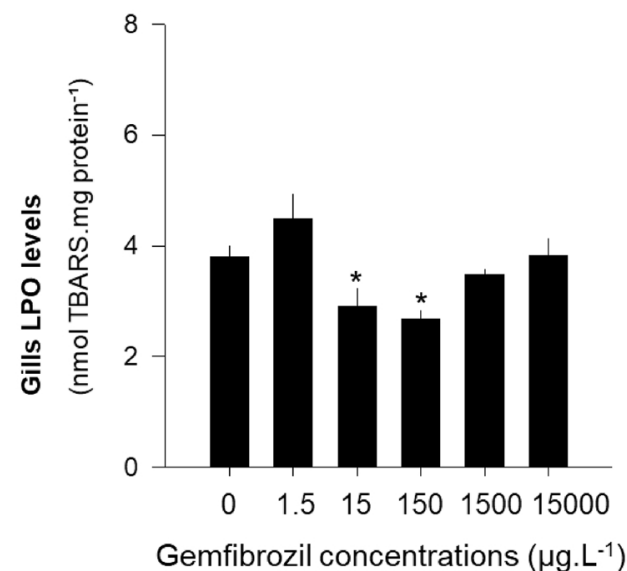

B)

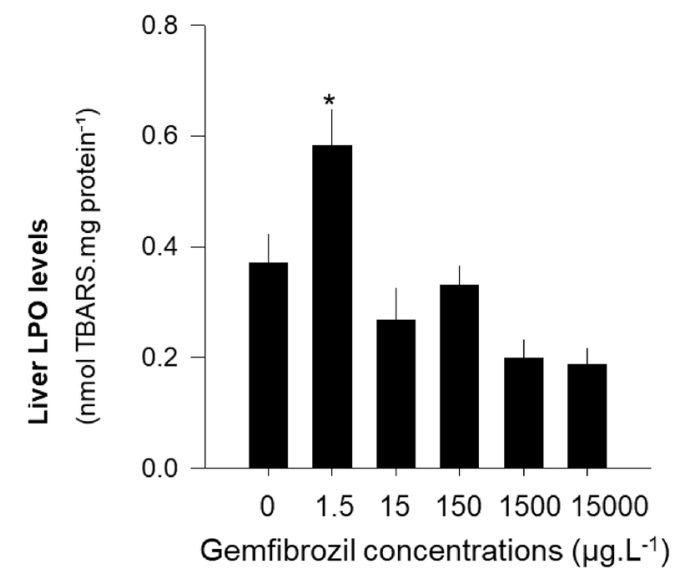

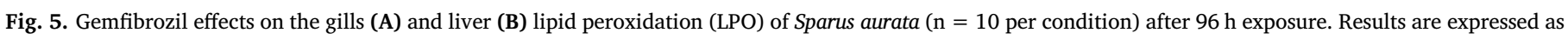
mean \pm standard error. *Significant differences to control (Dunnett's test, $p<0.05$ ).

were very different following exposure to GEM. CAT appeared as more responsive in gills than in the liver whereas GST and GR displayed overall similar profiles of response in both tissues. GPx, however, was more responsive in liver. These detected differences may be explained by the enzymatic basal activities. CAT basal activity was lower in gills than in the liver and GPx basal activity was lower in liver than in gills. Oxidative damage was only detected in liver at a concentration unable to activate enzymatic defences.
Although the mechanisms responsible for the effects of GEM is not known in detail, it is considered that many of the above-mentioned effects are mediated by GEM interaction with peroxisome proliferatoractivated receptor $\alpha$ (PPAR $\alpha$ ) (Al-Habsi et al., 2016; Marija et al., 2011; Staels et al., 1992), which is involved in the regulation of lipid metabolism in liver, heart, kidney and muscle (Marija et al., 2011; Pyper et al., 2010; Schoonjans et al., 1996). PPARa may be activated by natural ligands and synthetic agents, including fibrates (such as GEM) 

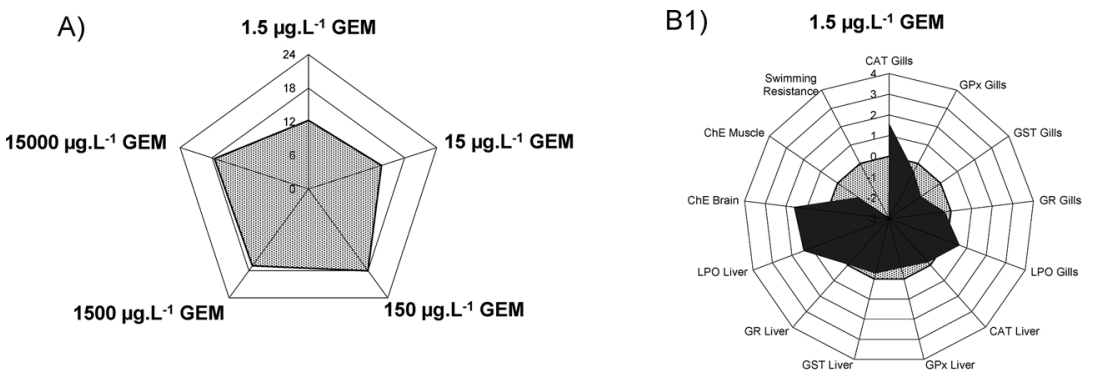

B3)

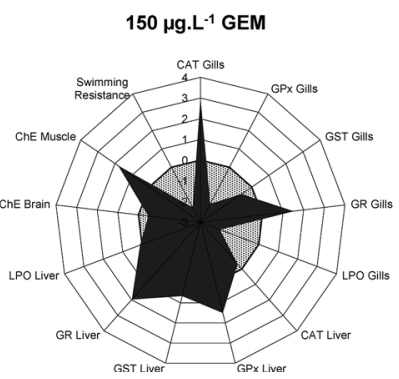

B4)

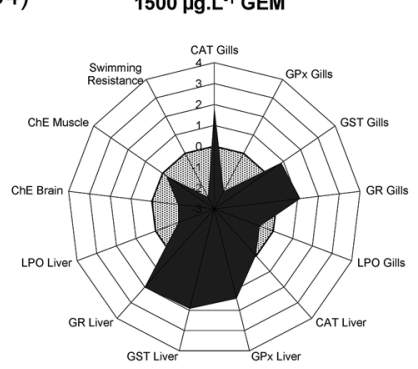

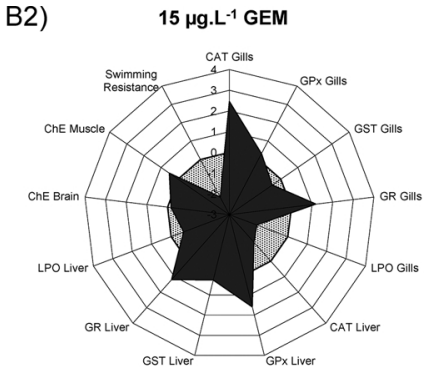

B5)

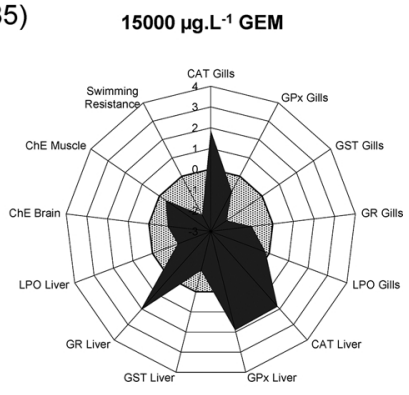

Fig. 6. Integrated biomarker response version 2 (IBRv2) (A) and assessed endpoints star plots for each experimental condition (B1-B5). Gemfibrozil (GEM); Cholinesterase (ChE); Catalase (CAT); Glutathione $S$-transferases (GST); Glutathione peroxidase (GPx); Glutathione reductase (GR); Lipid peroxidation (LPO).

(Marija et al., 2011; Touyz and Schiffrin, 2006). Fibrates are known to induce proliferation of peroxisomes in liver cells with associated coordinated transcriptional activation of peroxisomal fatty acid $\beta$-oxidation system and production of reactive oxygen species (ROS) (Lores Arnaiz et al., 1997, 1995; Marija et al., 2011; Moody et al., 1991; Palma et al., 1991; Pyper et al., 2010; Schoonjans et al., 1996). Elevated concentrations of $\mathrm{H}_{2} \mathrm{O}_{2}$ stimulate lipid peroxidation, which this may explain the increase of LPO levels in the liver and the absence in the gills. On the other hand, gills are key organs for the direct action of waterborne pollutants since they are involved in a range of processes critical to survival (e.g. respiration, osmoregulation, excretion of nitrogenous residual products and regulation of the acid-base balance) (Evans, 1987; Oliveira et al., 2008, 2012), and also in immune functions involving oxidative processes (Rodrigues et al., 2016; Tkachenko et al., 2014). Gills are highly vulnerable to toxic chemicals, because their large surface area facilitates toxicant interaction and absorption (Evans, 1987; Oliveira et al., 2008), so it is expected that some enzymatic responses are activated more and primarily in gills than in the liver.

The integration of the data using IBR allows to visualize more clearly the specific responses of biomarkers for each tested condition (Beliaeff and Burgeot, 2002). The IBR provides a combination of a graphical synthesis of the different biomarker responses and a numeric value which integrates all these responses at once (Devin et al., 2014). Based on the IBRv2 values, the effects of the different concentrations of GEM would be ordered as follows: $150 \mu \mathrm{g} \mathrm{L}^{-1} \approx$ $15,000 \mu \mathrm{g} \mathrm{L}^{-1} \approx 1500 \mu \mathrm{g} \mathrm{L}^{-1}>15 \mu \mathrm{g} \mathrm{L}^{-1}>1.5 \mu \mathrm{gL}^{-1}$ (Fig. 6A). The similar IBRv2 values observed for 150,1500 and $15,000 \mu \mathrm{g} \mathrm{L}^{-1}$ may be explained by the similarity of the fish responses independent of the GEM concentration due to reasons described above. Although there was no concentration-response relationship for the tested biomarkers (Fig. 6A), the results show that exposure to GEM at concentrations between 150 and $15,000 \mu \mathrm{L} \mathrm{L}^{-1}$ caused more effects than exposure to 1.5 and $15 \mu \mathrm{g} \mathrm{L}^{-1}$. In general, analyzing the assessed endpoints star plots obtained with IBRv2, for each experimental condition (Fig. 6B1B5), it seems clear that GEM had more effects in terms of capability to swim against a flow of $S$. aurata, CAT and GR activities in gills and GPx and GR activities in liver. If the data analyses takes into account a weighing factor attributed to different biological levels of organization as suggested by Liu et al. $(2013,2015)$, the effects of the different concentrations of GEM would be ordered as follows: $150 \mu \mathrm{g} \mathrm{L}{ }^{-1} \approx 15,000 \mu \mathrm{g} . \mathrm{L}^{-1} \approx 1500 \mu \mathrm{g} \mathrm{L}{ }^{-1}>1.5 \mu \mathrm{g} \mathrm{L}^{-1} \approx 15 \mu \mathrm{g} \mathrm{L}^{-1}$ (Table S2). This data analysis, attributing a higher weighing factor to behavior, did, however, not alter the ranking of GEM impact. Considering the integration of the data from biochemical endpoints (CAT, GST, GPx and GR activities and LPO levels) per tissue (gills versus liver) - Table S3 - the IBRv2 values were higher in gills than in liver for 1.5, 15 and $150 \mu \mathrm{g} \mathrm{L}^{-1}$ of GEM. However, the IBRv2 values were similar between the two tissues for $1500 \mu \mathrm{g} \mathrm{L}^{-1}$ of GEM and for $15,000 \mu \mathrm{g} \mathrm{L}^{-1}$ the IBRv2 value was higher in liver than in gills.

The detection of GEM toxicity at an environmentally relevant concentration may be of concern, taking into account that fish are exposed to a variety of contaminants in their natural habitat, including pharmaceuticals sharing the toxicological properties of GEM. Further studies assessing effects of low GEM concentrations and longer exposure periods are encouraged to improve the knowledge about the mechanisms involved on the toxicity of fibrates to non-target organisms like marine fish and its ability to adapt to these compounds.

\section{Conclusions}

A multibiomarker approach showed that short-term exposure to an environmentally relevant concentration of gemfibrozil $\left(1.5 \mu \mathrm{g} \mathrm{L}^{-1}\right)$ induced behavioral alterations and oxidative damage in the liver of the marine fish Sparus aurata. At higher concentrations the activities of some enzymes involved in antioxidant defense (catalase, glutathione peroxidase and glutathione reductase) were induced. Although there was no concentration-response relationship for responses, it was clear that higher concentrations $\left(150,1500,15000 \mu \mathrm{g} \mathrm{L}^{-1}\right.$ ) had more effects on fish than lower concentrations $\left(1.5\right.$ and $\left.15 \mu \mathrm{g} \mathrm{L}^{-1}\right)$. The integrated biomarker response version 2 (IBRv2) was found to be a useful tool to combine the results from many biomarkers.

\section{Conflict of interest statement}

The authors declare that there are no conflicts of interest. 


\section{Acknowledgments}

This research was supported through the COMPETE - Operational Competitiveness Program and National Funds through FCT Foundation for Science and Technology, under the project "NANOAu Effects of Gold Nanoparticles to Aquatic Organisms" (FCT PTDC/MAREST/3399/2012) (FCOMP-01-0124-FEDER-029435), through FCT/ MCTES through national funds (PIDDAC), the cofounding by FEDER, within the PT2020 Partnership Agreement and Compete 2020 to CESAM (UID/AMB/50017 - POCI-01-0145-FEDER-007638) and UID/ QUI/50006/2013. A. Barreto has a doctoral fellowship from FCT (SFRH/BD/97624/2013); L. G. Luis had a fellowship from FCT (BI/ UI88/6881/2014). MO has financial support of the program Investigator FCT, co-funded by the Human Potential Operational Programme and European Social Fund (IF/00335(2015).

Al-Habsi, A.A., Massarsky, A., Moon, T.W., 2016. Exposure to gemfibrozil and atorvastatin affects cholesterol metabolism and steroid production in zebrafish (Danio rerio). Comp. Biochem. Physiol. Part B: Biochem. Mol. Biol. 199, 87-96.

Andreozzi, R., Raffaele, M., Nicklas, P., 2003. Pharmaceuticals in STP effluents and their solar photodegradation in aquatic environment. Chemosphere 50, 1319-1330.

Athar, M., Iqbal, M., 1998. Ferric nitrilotriacetate promotes $N$-diethylnitrosamine-induced renal tumorigenesis in the rat: implications for the involvement of oxidative stress. Carcinogenesis 19, 1133-1139.

Barreto, A., Luis, L.G., Soares, A.M.V.M., Paíga, P., Santos, L.H.M.L.M., Delerue-Matos, C., Hylland, K., Loureiro, S., Oliveira, M., 2017. Genotoxicity of gemfibrozil in the gilthead seabream (Sparus aurata). Mutat. Res. Genet. Toxicol. Environ. Mutagen. 821, 36-42.

Beliaeff, B., Burgeot, T., 2002. Integrated biomarker response: a useful tool for ecological risk assessment. Environ. Toxicol. Chem. 21, 1316-1322.

Bradford, M.M., 1976. A rapid and sensitive method for the quantitation of microgram quantities of protein utilizing the principle of protein-dye binding. Anal. Biochem. 72, 248-254.

Bulloch, D.N., Lavado, R., Forsgren, K.L., Beni, S., Schlenk, D., Larive, C.K., 2012. Analytical and biological characterization of halogenated gemfibrozil produced through chlorination of wastewater. Environ. Sci. Technol. 46, 5583-5589.

Carlberg, I., Mannervik, B., 1975. Purification and characterization of the flavoenzyme glutathione reductase from rat liver. J. Biol. Chem. 250, 5475-5480.

Ceyhun, S.B., Şentürk, M., Ekinci, D., Erdoğan, O., Çiltaş, A., Kocaman, E.M., 2010. Deltamethrin attenuates antioxidant defense system and induces the expression of heat shock protein 70 in rainbow trout. Comp. Biochem. Physiol. Part C: Toxicol. Pharmacol. 152, 215-223.

Claiborne, A., 1985. Catalase activity. CRC Handbook of Methods for Oxygen Radical Research 1. pp. 283-284.

Devin, S., Burgeot, T., Giambérini, L., Minguez, L., Pain-Devin, S., 2014. The integrated biomarker response revisited: optimization to avoid misuse. Environ. Sci. Pollut. Res. $21,2448-2454$.

Ellman, G.L., Courtney, K.D., Andres Jr., V., Featherstone, R.M., 1961. A new and rapid colorimetric determination of acetylcholinesterase activity. Biochem. Pharmacol. 7 88-95.

Evans, D.H., 1987. The fish gill: site of action and model for toxic effects of environmental pollutants. Environ. Health Perspect. 71, 47-58.

Fang, Y., Karnjanapiboonwong, A., Chase, D.A., Wang, J., Morse, A.N., Anderson, T.A., 2012. Occurrence, fate, and persistence of gemfibrozil in water and soil. Environ. Toxicol. Chem. 31, 550-555.

Fraz, S., Lee, A.H., Wilson, J.Y., 2018. Gemfibrozil and carbamazepine decrease steroid production in zebrafish testes (Danio rerio). Aquat. Toxicol. 198, 1-9.

Fent, K., Weston, A.A., Caminada, D., 2006. Ecotoxicology of human pharmaceuticals. Aquat. Toxicol. 76, 122-159.

Franco, J.L., Trivella, D.B.B., Trevisan, R., Dinslaken, D.F., Marques, M.R.F., Bainy, A.C.D., Dafre, A.L., 2006. Antioxidant status and stress proteins in the gills of the brown mussel Perna perna exposed to zinc. Chem. Biol. Interact. 160, 232-240.

Frasco, M.F., Guilhermino, L., 2002. Effects of dimethoate and beta-naphthoflavone on selected biomarkers of Poecilia reticulata. Fish Physiol. Biochem. 26, 149-156.

Gaw, S., Thomas, K.V., Hutchinson, T.H., 2014. Sources, impacts and trends of pharmaceuticals in the marine and coastal environment. Philos. Trans. R. Soc. B: Biol. Sci. 369, 20130572

Gros, M., Petrović, M., Barceló, D., 2006. Development of a multi-residue analytical methodology based on liquid chromatography-tandem mass spectrometry (LC-MS MS) for screening and trace level determination of pharmaceuticals in surface and wastewaters. Talanta 70, 678-690.

Guilhermino, L., Lopes, M.C., Carvalho, A.P., Soares, A., 1996. Acetylcholinesterase activity in juveniles of Daphnia magna straus. Bull. Environ. Contam. Toxicol. 57, 979-985.

Habig, W.H., Pabst, M.J., Jakoby, W.B., 1974. Glutathione S-transferases. The first enzymatic step in mercapturic acid formation. J. Biol. Chem. 249, 7130-7139.

Henriques, J.F., Almeida, A.R., Andrade, T., Koba, O., Golovko, O., Soares, A.M.V.M., Oliveira, M., Domingues, I., 2016. Effects of the lipid regulator drug gemfibrozil: a toxicological and behavioral perspective. Aquat. Toxicol. 170, 355-364.

Hernández-Moreno, D., Pérez-López, M., Soler, F., Gravato, C., Guilhermino, L., 2011. Effects of carbofuran on the sea bass (Dicentrarchus labrax L.): study of biomarkers and behaviour alterations. Ecotoxicol. Environ. Safe 74, 1905-1912.

Ido, A., Hiromori, Y., Meng, L., Usuda, H., Nagase, H., Yang, M., Hu, J., Nakanishi, T., 2017. Occurrence of fibrates and their metabolites in source and drinking water in Shanghai and Zhejiang, China. Sci. Rep. 7, 45931.

Jackevicius, C.A., Tu, J.V., Ross, J.S., Ko, D.T., Carreon, D., Krumholz, H.M., 2011. Use of fibrates in the United States and Canada. JAMA 305, 1217-1224.

Kennedy, C.J., Farrell, A.P., 2006. Effects of exposure to the water-soluble fraction of crude oil on the swimming performance and the metabolic and ionic recovery postexercise in Pacific herring (Clupea pallasi). Environ. Toxicol. Chem. 25, 2715-2724.

Kim, K., Kleinman, H.K., Lee, H.-J., Pahan, K., 2017. Safety and potential efficacy of gemfibrozil as a supportive treatment for children with late infantile neuronal ceroid lipofuscinosis and other lipid storage disorders. Orphanet J. Rare Dis. 12, 113.

Lima, I., Moreira, S.M., Osten, J.R.-V., Soares, A.M.V.M., Guilhermino, L., 2007. Biochemical responses of the marine mussel Mytilus galloprovincialis to petrochemical environmental contamination along the North-western coast of Portugal. Chemosphere 66, 1230-1242.

Lin, A.Y., Reinhard, M., 2005. Photodegradation of common environmental pharmaceuticals and estrogens in river water. Environ. Toxicol. Chem. 24, 1303-1309.

Liu, C., Chang, V.W.C., Gin, K.Y.H., 2013. Environmental toxicity of PFCs: an enhanced integrated biomarker assessment and structure-activity analysis. Environ. Toxicol. Chem. 32, 2226-2233.

Liu, J., Lu, G., Zhang, Z., Bao, Y., Liu, F., Wu, D., Wang, Y., 2015. Biological effects and bioaccumulation of pharmaceutically active compounds in crucian carp caged near the outfall of a sewage treatment plant. Environ. Sci. Process. Impacts 17, 54-61.

Lores Arnaiz, S., Travacio, M., Llesuy, S., Boveris, A., 1995. Hydrogen peroxide metabolism during peroxisome proliferation by fenofibrate. Biochim. Biophys. Acta (BBA) - Mol. Basis Dis. 1272, 175-180.

Lores Arnaiz, S., Travacio, M., Monserrat, A.J., Cutrín, J.C., Llesuy, S., Boveris, A., 1997. Chemiluminescence and antioxidant levels during peroxisome proliferation by fenofibrate. Biochim. Biophys. Acta (BBA) - Mol. Basis Dis. 1360, 222-228.

Lushchak, V.I., 2016. Contaminant-induced oxidative stress in fish: a mechanistic approach. Fish Physiol. Biochem. 42, 711-747.

Lyssimachou, A., Thibaut, R., Gisbert, E., Porte, C., 2014. Gemfibrozil modulates cytochrome P450 and peroxisome proliferation-inducible enzymes in the liver of the yellow European eel (Anguilla anguilla). Environ. Sci. Pollut. Res. 21, 862-871.

Marija, M., Paško, K., Jasna, L., Marijan, K., Marta, K., Nada, V., Vlasta, B., 2011. The influence of gemfibrozil on malondialdehyde level and paraoxonase 1 activity in wistar and fisher rats. Basic Clin. Pharmacol. Toxicol. 108, 428-435.

Mimeault, C., Trudeau, V.L., Moon, T.W., 2006. Waterborne gemfibrozil challenges the hepatic antioxidant defense system and down-regulates peroxisome proliferator-activated receptor beta (PPAR $\beta$ ) mRNA levels in male goldfish (Carassius auratus). Toxicology 228, 140-150.

Mimeault, C., Woodhouse, A.J., Miao, X.S., Metcalfe, C.D., Moon, T.W., Trudeau, V.L., 2005. The human lipid regulator, gemfibrozil bioconcentrates and reduces testosterone in the goldfish, Carassius auratus. Aquat. Toxicol. 73, 44-54.

Mohandas, J., Marshall, J.J., Duggin, G.G., Horvath, J.S., Tiller, D.J., 1984. Differential distribution of glutathione and glutathione-related enzymes in rabbit kidney. Biochem. Pharmacol. 33, 1801-1807.

Moody, D.E., Reddy, J.K., Lake, B.G., Popp, J.A., Reese, D.H., 1991. Peroxisome proliferation and nongenotoxic carcinogenesis: commentary on a symposium. Fundam. Appl. Toxicol. 16, 233-248.

Nunes, B., Carvalho, F., Guilhermino, L., 2004. Acute and chronic effects of clofibrate and clofibric acid on the enzymes acetylcholinesterase, lactate dehydrogenase and catalase of the mosquitofish, Gambusia holbrooki. Chemosphere 57, 1581-1589.

OECD, 1992. Test No. 203: Fish, Acute Toxicity Test. OECD Publishing.

Ohkawa, H., Ohishi, N., Yagi, K., 1979. Assay for lipid peroxides in animal tissues by thiobarbituric acid reaction. Anal. Biochem. 95, 351-358.

Oliveira, M., Gravato, C., Guilhermino, L., 2012. Acute toxic effects of pyrene on Pomatoschistus microps (Teleostei, Gobiidae): mortality, biomarkers and swimming performance. Ecol. Indic. 19, 206-214.

Oliveira, M., Cardoso, D.N., Soares, A.M.V.M., Loureiro, S., 2015. Effects of short-term exposure to fluoxetine and carbamazepine to the collembolan Folsomia candida. Chemosphere 120, 86-91.

Oliveira, M., Pacheco, M., Santos, M.A., 2008. Organ specific antioxidant responses in golden grey mullet (Liza aurata) following a short-term exposure to phenanthrene. Sci. Total Environ. 396, 70-78.

Ozansoy, G., Akin, B., Aktan, F., Karasu, Ç., 2001. Short-term gemfibrozil treatment reverses lipid profile and peroxidation but does not alter blood glucose and tissue antioxidant enzymes in chronically diabetic rats. Mol. Cell. Biochem. 216, 59-63.

Palma, J., Garrido, M., Rodríguez-García, M.I., del Río, L.A., 1991. Peroxisome proliferation and oxidative stress mediated by activated oxygen species in plant peroxisomes. Arch. Biochem. Biophys. 287, 68-74.

Pan, J.-F., Buffet, P.-E., Poirier, L., Amiard-Triquet, C., Gilliland, D., Joubert, Y., Pilet, P., Guibbolini, M., Risso de Faverney, C., Roméo, M., Valsami-Jones, E., Mouneyrac, C., 2012. Size dependent bioaccumulation and ecotoxicity of gold nanoparticles in an endobenthic invertebrate: the tellinid clam Scrobicularia plana. Environ. Pollut. 168, 
$37-43$.

Prindiville, J.S., Mennigen, J.A., Zamora, J.M., Moon, T.W., Weber, J.-M., 2011. The fibrate drug gemfibrozil disrupts lipoprotein metabolism in rainbow trout. Toxicol. Appl. Pharmacol. 251, 201-208.

Pyper, S.R., Viswakarma, N., Yu, S., Reddy, J.K., 2010. PPARa: energy combustion, hypolipidemia, inflammation and cancer. Nucl. Recept. Signal. 8, e002.

Qu, B., Li, Q.-T., Wong, K.P., Tan, T.M.C., Halliwell, B., 2001. Mechanism of clofibrate hepatotoxicity: mitochondrial damage and oxidative stress in hepatocytes. Free Radic. Biol. Med. 31, 659-669.

Quinn, B., Gagne, F., Blaise, C., 2008. An investigation into the acute and chronic toxicity of eleven pharmaceuticals (and their solvents) found in wastewater effluent on the cnidarian, Hydra attenuata. Sci. Total Environ. 389, 306-314.

Quinn, B., Schmidt, W., O’Rourke, K., Hernan, R., 2011. Effects of the pharmaceuticals gemfibrozil and diclofenac on biomarker expression in the zebra mussel (Dreissena polymorpha) and their comparison with standardised toxicity tests. Chemosphere 84, 657-663.

Rodrigues, S., Antunes, S.C., Correia, A.T., Nunes, B., 2016. Acute and chronic effects of erythromycin exposure on oxidative stress and genotoxicity parameters of Oncorhynchus mykiss. Sci. Total Environ. 545-546, 591-600.

Roy, A., Pahan, K., 2009. Gemfibrozil, stretching arms beyond lipid lowering. Immunopharmacol. Immunotoxicol. 31, 339-351.

Salesa, B., Ferrando, M.D., Villarroel, M.J., Sancho, E., 2017. Effect of the lipid regulator Gemfibrozil in the Cladocera Daphnia magna at different temperatures. J. Environ. Sci. Health Part A Toxic Hazard. Subst. Environ. Eng. 52, 228-234.

Sanchez, W., Burgeot, T., Porcher, J.-M., 2013. A novel "Integrated biomarker response" calculation based on reference deviation concept. Environ. Sci. Pollut. Res. 20, 2721-2725.

Sanderson, H., Johnson, D.J., Wilson, C.J., Brain, R.A., Solomon, K.R., 2003. Probabilistic hazard assessment of environmentally occurring pharmaceuticals toxicity to fish, daphnids and algae by ECOSAR screening. Toxicol. Lett. 144, 383-395.

Schmidt, W., O'Rourke, K., Hernan, R., Quinn, B., 2011. Effects of the pharmaceuticals gemfibrozil and diclofenac on the marine mussel (Mytilus spp.) and their comparison with standardized toxicity tests. Mar. Pollut. Bull. 62, 1389-1395.

Schmidt, W., Rainville, L.-C., McEneff, G., Sheehan, D., Quinn, B., 2014. A proteomic evaluation of the effects of the pharmaceuticals diclofenac and gemfibrozil on marine mussels (Mytilus spp.): evidence for chronic sublethal effects on stress-response proteins. Drug Test. Anal. 6, 210-219.

Schoonjans, K., Staels, B., Auwerx, J., 1996. The peroxisome proliferator activated receptors (PPARs) and their effects on lipid metabolism and adipocyte differentiation. Biochim. Biophys. Acta (BBA) - Lipids Lipid Metab. 1302, 93-109.

Skolness, S.Y., Durhan, E.J., Jensen, K.M., Kahl, M.D., Makynen, E.A., Villeneuve, D.L., Ankley, G.T., 2012. Effects of gemfibrozil on lipid metabolism, steroidogenesis, and reproduction in the fathead minnow (Pimephales promelas). Environ. Toxicol. Chem. 31, 2615-2624.

Solé, M., Fortuny, A., Mañanós, E., 2014. Effects of selected xenobiotics on hepatic and plasmatic biomarkers in juveniles of Solea senegalensis. Environ. Res. 135, 227-235.

Souid, G., Souayed, N., Yaktiti, F., Maaroufi, K., 2013. Effect of acute cadmium exposure on metal accumulation and oxidative stress biomarkers of Sparus aurata. Ecotoxicol. Environ. Safe 89, 1-7.

Souid, G., Souayed, N., Yaktiti, F., Maaroufi, K., 2015. Lead accumulation pattern and molecular biomarkers of oxidative stress in seabream (Sparus aurata) under shortterm metal treatment. Drug Chem. Toxicol. 38, 98-105.

Staels, B., van Tol, A., Andreu, T., Auwerx, J., 1992. Fibrates influence the expression of genes involved in lipoprotein metabolism in a tissue-selective manner in the rat. Arterioscler. Thromb. Vasc. Biol. 12, 286-294.

Steinkey, D., Lari, E., Woodman, S.G., Luong, K.H., Wong, C.S., Pyle, G.G., 2018. Effects of gemfibrozil on the growth, reproduction, and energy stores of Daphnia magna in the presence of varying food concentrations. Chemosphere 192, 75-80.

Sureda, A., Capó, X., Busquets-Cortés, C., Tejada, S., 2018. Acute exposure to sunscreen containing titanium induces an adaptive response and oxidative stress in Mytillus galloprovincialis. Ecotoxicol. Environ. Safe 149, 58-63.

Sutken, E., Inal, M., Ozdemir, F., 2006. Effects of vitamin e and gemfibrozil on lipid profiles, lipid peroxidation and antioxidant status in the elderly and young hyperlipidemic subjects. Saudi Med. J. 27, 453-459.

Svendsen, J.C., Tirsgaard, B., Cordero, G.A., Steffensen, J.F., 2015. Intraspecific variation in aerobic and anaerobic locomotion: gilthead sea bream (Sparus aurata) and Trinidadian guppy (Poecilia reticulata) do not exhibit a trade-off between maximum sustained swimming speed and minimum cost of transport. Front. Physiol. 6, 43.

Teles, M., Fierro-Castro, C., Na-Phatthalung, P., Tvarijonaviciute, A., Soares, A.M.V.M., Tort, L., Oliveira, M., 2016. Evaluation of gemfibrozil effects on a marine fish (Sparus aurata) combining gene expression with conventional endocrine and biochemical endpoints. J. Hazard. Mater. 318, 600-607.

Tkachenko, H., Kurhaluk, N., Grudniewska, J., Andriichuk, A., 2014. Tissue-specific responses of oxidative stress biomarkers and antioxidant defenses in rainbow trout Oncorhynchus mykiss during a vaccination against furunculosis. Fish Physiol. Biochem. 40, 1289-1300.

Togola, A., Budzinski, H., 2007. Analytical development for analysis of pharmaceuticals in water samples by SPE and GC-MS. Anal. Bioanal. Chem. 388, 627-635.

Touyz, R.M., Schiffrin, E.L., 2006. Peroxisome proliferator-activated receptors in vascular biology-molecular mechanisms and clinical implications. Vasc. Pharmacol. 45, 19-28.

Vidal-Dorsch, D.E., Bay, S.M., Maruya, K., Snyder, S.A., Trenholm, R.A., Vanderford, B.J., 2012. Contaminants of emerging concern in municipal wastewater effluents and marine receiving water. Environ. Toxicol. Chem. 31, 2674-2682.

Vieira, L.R., Gravato, C., Soares, A.M.V.M., Morgado, F., Guilhermino, L., 2009. Acute effects of copper and mercury on the estuarine fish Pomatoschistus microps: linking biomarkers to behaviour. Chemosphere 76, 1416-1427.

Wilhelm Filho, D., Tribess, T., Gáspari, C., Claudio, F.D., Torres, M.A., Magalhães, A.R.M., 2001. Seasonal changes in antioxidant defenses of the digestive gland of the brown mussel (Perna perna). Aquaculture 203, 149-158.

Wolter, C., Arlinghaus, R., 2003. Navigation impacts on freshwater fish assemblages: the ecological relevance of swimming performance. Rev. Fish Biol. Fish. 13, 63-89.

Zurita, J.L., Repetto, G., Jos, Á., Salguero, M., López-Artíguez, M., Cameán, A.M., 2007. Toxicological effects of the lipid regulator gemfibrozil in four aquatic systems. Aquat. Toxicol. 81, 106-115. 